\title{
Extra-Legal and Shadow Functioning of Public Authorities
}

\author{
Alexey I. Ovchinnikov \\ Alexey Y. Mamychev \\ Svetlana F. Litvinova \\ Vladivostok State University Economics and Service \\ Email: eldirect@mail.ru,k_fp3@mail.ru
}

\section{Doi:10.5901/mjss.2015.v6n3p387}

\begin{abstract}
This article discusses the various forms of public authorities functioning and state authorities functioning in particular. The authors argue that in addition to the institutional and regulatory and structural and functional characteristics, public authority realizes in extra-legal form, which acts as a complex concept correlating with such forms as "informal", "shadow", "unlawful." It is proved that this form of governmental authority is not mediated by law and can have both formal public and informal, shadow and non-legal nature. The matter of this article shows that extralegal forms of activity lead not only to negative, but also to positive effects - to the development of the system of state power, political forms and regime, methods of state and legal impact on the political, economic, social and other systems of society. Thus, in some cases extralegal but legitimated by society forms of state influence on the political process can get institutional and regulatory clearance. Moreover, the authors identify the causes and factors of the development of this form, as well as provide a meaningful analysis of the informal authorities' activity, their shadow interaction and shadow forms of relations, illegal practices, unlawful sphere and shadow law.
\end{abstract}

Keywords: extra-legal activities, the State, political system, public authority, shadow law;

\section{Introduction}

Traditionally, the activity of public authority in the political system is considered in the institutional and regulatory, structural and functional aspects, which, of course, are important for its functioning. Through their analysis one reveals the essence, the main functions and tasks, social purpose and role of the public authority in the life of society. However, it is clear that this is not the only form of public authority and its interaction with other political subjects. There are a variety of forms of representation of public authority, and above all the state authority in the political life of society. Today those forms are studied not enough. Those forms include, first of all, "extra-legal" and "shadow" activities of public authorities in the modern state and legal process.

In this regard A.I. Solovyov correctly points up that the system of governmental authorities, the role and place of the public authorities and the specifics of its functioning in the political system is considered, "usually through a list of its organizational principles and functions (dysfunctions), the activities of the bureaucracy, especially the institutional structure and its parameters that eventually revealing the political, administrative and legal nature of this phenomenon. However, in this quite rightful approach in general one primarily studied the legal space of public administration, and all its other manifestations almost were automatically referred to private deviations and splashes of "birthmarks" outliving by its evolution"(A.I. Solovyov 2011). Actually, well-known researcher Stefan Lux rightfully noted that it is quite important while analyzing of the phenomenon of "authority", authorities relations unfolding in society "to take into account those aspects that are least amenable to observation, for power, without a doubt, the more effective the less it is noticeable" (S. Lux, 2010).

Therefore, the analysis of public authority in modern society requires consideration of the various forms of its functioning, which goes far beyond the traditional structural-functional and institutional and regulatory analysis. Moreover, it should be stated that the development of the political system, its form of organization, complexity of the structure of needs, the emergence of new risks and threats at the present stage of evolution of the state and legal activity allow to point out an increasing role of public authorities and, above all, the state authority, as well as public management technologies in people's lives. 


\section{Literature Review}

Traditionally, the state authority is analyzing either as the main subject, the central element (subsystem) of the political system (I.A. Ivannikov, 1995), or as a system of state bodies (V.Y. Lyubashits, 2001), specific organizational and legal forms of activity (I.N. Homerov, 2002), or the system of controlling power (A.F. Malyi, 2001) and so on. If one organizes a variety of specialized researches on the state authorities, it is easy to see that it is exactly the legal and institutional, structural and functional approaches prevail in the interpretation of the notion, characteristics and concept of this form of public authority.

The most famous and fundamental research, analyzing extra-legal activities of public authorities, are the works of German political scientist and lawyer Carl Schmitt. For him extralegal activity in general stands for a criterion of "confirmation" of the dominating rule authority in the state; the ability to extra-legal forms of exercise of power is an attributive quality of any state will, its distinguishing feature from other forms of political power. German political scientist believes that the legal regulations provide a mode of law and order, require the homogeneous situation, since the norm is known is regulated be the already existing typical social relations: "Norm requires averaged homogeneous situation. Really this normality is not just external prerequisite which can be ignored by a lawyer; on the contrary, it is directly related to the norm immanent activity rules. There are no rules applicable to chaos. Order must be set first: only then the legal system makes sense "(C. Schmitt, 2000).

In this regard, the meaning and purpose of the supreme, sovereign state authority are in creation of this "normal situation"; chaos, instability, transition, etc. must first be ordered by sovereign authority. Exactly the state authority in its extralegal activities (since the rule of law does not provide and cannot provide forms, methods and modes of operation of authorities in a period of instability, chaos, emergency, here it is powerless), "creates a normal situation". In other words, only the government authority makes the final power-volitional decision, whether the state of normality and certain political order, which expresses this "situation of normality" will reign or not. In this case, every law is "a law which is applicable to the concrete situation". Hence, the essence of state authority, according to Carl Schmitt, "would be correct to identify not as sanctions or power monopoly, but as the monopoly of the solution ... An exceptional case makes the nature of state power clear and more obvious. There solutions differ from the legal norms; the authority demonstrates that does not need law to create law ... An exceptional case is more interesting than the normal case. Last proves nothing, but the exception proves everything; it not only confirms the rule: the rule itself consists of exceptions"(C. Schmitt, 2000).

Even in a relatively steady state of the political system operation, i.e., when, for example, the democratic configuration of public-authoritative interaction between the individual, society and the state is developed, there are periods of so-called "extra-legal agreement" concerning national development strategies, priorities of a legal policy, etc., forming a "political corridor of opportunities" based on the civilian trust and recognition of the political agenda (S.M. Lipset, 1994). This social cohesion and trust can legitimate special activities of no legal clearance aimed at accelerating the solution of acute national problems, needs and interests: "Receiving from the citizens this or that degree of credibility, the state forms some political corridor of opportunities for its administrative apparatus, in which the state performs timely and direct management of public relations" (A.I. Solovyov, 2011).

In modern scientific literature it is proved that forms of government influence on social processes which are extralegal, but legitimated by society, can gain (due to its success, effectiveness, usefulness, adequacy of socio-political development of the society) institutional and regulatory clearance (R. Barker, 2003; and E.A. Ostrom, 2010; and M.S. Weatherford, 1992).

In this context, it is appropriate to emphasize the fact that at the state level national interests (balanced and harmonized interests of an individual, society and the state) are in themselves quite abstract, their content is like "floating frame of interpretation" that allows state authorities not only to "subjectivized" the managerial emphasis and priorities, but also to choose a more efficient and cost-effective forms and methods of their implementation in respect to technological and bureaucratic type of political rationality.

It should be noted for Russian legal and political mentality extra-legal forms of state authority activities, the practice of creating temporary, emergency and other public institutions of government to address the emerging challenges, risks and threats are quite traditional. For example, according to the well-known historian and political scientist, one of the most important and characteristic properties of the Russian system of public administration is in its extralegal or, more precisely, non-institutional and non-legal character. Here, the "main element, the actor of administration is not the institution but all kinds of "emergency committee"(EC). The difference between the institution and the $E C$ is that the first one is a constitutional body; its existence is enshrined in the basic regulations; it operates within the boundaries of the legal field, its function is not limited in time, the powers are clearly defined and known to the public ... Second ones are created when the problems of administrating cannot be solved by institutions. The existence of the EC is not enshrined in 
the basic regulations. For these bodies is possible going beyond law; their actions are often of semi-secret (or even private) character; in any case, the society is not completely aware of the EC activities" (Y.S. Pivovarov, 2006).

In the Russian researches extralegal activity of public authorities, related primarily to ideocratic element of its functioning was also analyzed. There ordinarily political, legal and economic institutions and establishments had no selfvaluable and self-sufficient status as observed in the western political and legal tradition (where the fetishization of political and legal institutions takes place), and were of secondary values and applied, but provided a representation and implementation of the values of the primary nature, such as social truth, justice, order, harmony, spiritual and moral freedom, etc. At the same time the effectiveness of public and legal life was determined by the belief in the truth, in social justice, as respect for the truth meant much more than reasonable laws and rationally organized legal-political and socioeconomic institutions.

These methodological views on extra-legal activity of the government authority are based on the fact that the existing social, political and legal values are unequal and of different character, have different socio-cultural, spiritual and moral content and meaning. For example, the specific political and legal order sets and support through legal and political institutions, mechanisms and means certain order, the desired social and legal status (reconciliational Wednesday Kistyakovsky B.A.), in the context of which political subjects meet private and public interests and needs.

However, in this case, the socio-cultural values is the very order of relations; the concrete legal, social, political institutions and mechanisms are the only means, the instrument of its realization and maintaining, i.e. presented as the values of the second value. Because of that, the political institutions and government establishments, models and mechanisms of interaction at the level of public discourse form (must form!) united public-authoritative environment of social relations development and functioning, which in its turn provides the ordering of social relations and reflects the specificity and patterns of socio-cultural system development (L. Kirsanova and O. Korotina, 2014).

\section{Methods and Materials}

Extra-legal form of public authority activity will be considered by us as an inclusive and broad (in terms of content) concept in relation to such forms as "informal" and "shadow" activities, since the latter are extra-legal by definition, i.e. not regulated by the rights or violate the legal establishment. It certainly does not mean that these forms of activity are negative factors of state-legal process development. On the contrary, quite often extra-legal forms of activity lead to positive effects - to the development of the system of state authority, forms, modes, methods of state and legal impact on the political system, the social organization as a whole. In other words, extra-legal activity is expressed in a variety of formal and informal activities of state bodies, their officials, which is not mediated by law, or contrary to it (violates functioning law).

From the theoretical and methodological point of view let's select a set of factors that we believe affect the development of extra-legal and shadow activities of public authority:

- extralegal activities associated with the crisis, emergency or other unusual situations, as well as with the characteristic of the transitive period of social and political effects of anomia and dysnomia;

- formation in the state and legal practice "extra-legal agreement" concerning national development strategies, priorities and legal policy, etc., forming a "political corridor of opportunity", based on the civil trust and recognition of the political agenda;

- dynamism and sometimes uniqueness of social relations, which are of state concern, form situations in which not every socio-political phenomena and processes is predetermined by the legal norm and require mobile extra-legal activity;

- the emergence and development of deformations in the political and legal mentality of citizens, officials, as well as effectiveness and legitimacy of the activities of public bodies and government structures reducing;

- the development of simulation authoritarian democratic political systems, which are quite often using extralegal forms of state activity in which in order to legitimize state authority the "ritualization" of electoral system, virtualization of social and political activity of the state machinery, the illusory nature of submission of the political elite, "floating frames" of justice and political double standards, "indicative character" of legal activity of the population, as well as assessment (quantitative, statistical, not quality) of law and order on formal indicators, etc. are performed.

\section{Findings and Discussion}

Extra-legal form - is the activity of public authority which is not associated with law or meditated by rights (although in 
some cases it may not be settled by law, but complies with the applicable constitutional and legal system and the spirit of the institutional and legal order) and can have both formal and public and informal, shadow and non-legal characteristics.

It is important to emphasize that the extra-legal form of public authority, and especially the leading form of public power - the state authority, just as important and significant as the legal one: in the same way as the legal form of activity, it expresses the essence and purpose of a political institution, it specifies its essence, methods and means for impact on public and social processes, etc. From the viewpoint of A.M. Vitchenko real political practice "shows that not all government commands go through the formalities of the rights. If one accepts that the government operates only within the law, one has to admit that the lack of legal establishment in any sphere of public life will inevitably lead to government inaction in cases where the state task cannot be solved due to the fact that it does not fit in the previously published normative act. Legal registration of state activity is not a comprehensive factor"(A.M. Vitchenko, 1982).

In theoretical and practical terms, extra-legal activities of public authorities can be examined in various aspects. This is due primarily to the fact that the legal regulation, as rightly pointed out by A.M. Vitchenko, does not absorb all the commands of the state without exception. The possibility of free public authorities will has a discretion in many areas of its activity. The state also commands if "the law is silent". The reason is not only in complex and multifaceted activities of the state, but also in dynamic and sometimes uniqueness of social relations, with which the state deals (O. Kononova and Z. Yakimova, 2013). That is why in public life sometimes there is a situation in which not every case of authority solutions can be predetermined by the legal norm" (A.M. Vitchenko, 1982).

The development of extra-legal forms of government activity is connected with the legal structure of its operation, namely with emerging deformations in the political and legal mentality of citizens, officials; with low efficiency and legitimacy of law-enforcement bodies and other law machinery functioning; with effects of legal and political anomia and dysnomia emerging during the transition period of political organization. In which connection these deformations is expressed in mass phenomena of political, legal and moral infantilism (disformed and gaped legal and moral, ethical attitudes, knowledge, sets, ideas, ideals, etc.), nihilism (ignoring the moral values, the law, the denial of social significance and value of social and legal systems and so on.), criminalization (fusion of legal consciousness of citizens, law enforcement officials and other authorities with criminal structures).

In addition the deformation is conditioned by the processes of stereotyping - the formation of political and legal cliches and stereotypes in the process of public-authoritative activities. As P.P. Baranov points out, the most typical for this form of deformation are patterns, for example, of accusatory characteristics in the authoritative-legal interactions of authorized officials with citizens; presumption of self-righteousness in addressing professional issues; stereotypes of closeness (almost "legal sacredness") of internal authoritative-legal activities and rigid internal psychological "selfcensorship"; focus on toughening of penalties and so on. (P.P. Baranov, 2005).

According to the researcher, these deformations produce not only all spheres, but also all levels of political culture and consciousness. They invade the area of specialized knowledge enjoyed by citizens and officials, destroy the political, legal and moral principles, feelings, beliefs, distort the political, legal and moral and spiritual outlook. Modern deformations of political and legal consciousness is largely correlated with the transitivity of social and political organization of Russian society, traditional values and ideological orientations of development breaking, spiritual and moral disorientation and social anomia. All this leads to a nihilistic attitude to the law and current political reality. Nihilistic attitude to the political order and law, beyond question, is a destructive factor, destroying political organization of society itself and its values, and stimulate the process of corruption of political and legal consciousness, etc.

It is well known that the subjective structure of a nihilistic attitude includes some individuals who are prone in their legal consciousness and behavior to delinquent and criminal forms of realization of their interests and needs; social groups organized in order to achieve their ideological and material goals by illegal, immoral or informal means; and also state officials, officers, departmental management units, etc.

In its turn, the shadow relations exist and develop in different sectors of the state and legal activity, which are characterized by informational untransparentness of certain types and models of authoritative relations of subjects in society and the state observation. However, their difference from, for example, informal relationships, is that if the formal and informal authoritative relations are organic processes of social development, which are reinforcing each other (of course, sometimes contradicting each other), the shadow relations arising out as a result these processes represent a conscious "retreat" from the existing official legal and regulatory models and authoritative-legal forms of economic, political, legal activity of society.

In other words, the shadow authoritative relations - is interaction on the achievement of certain social and political objectives and needs implemented in the "shadow (hidden) spectrum of events", there is no information from "outside" (beyond these interactions) comes in and does not no applied to the official statistics and public control, i.e., in the field of information untransparentness (R.V. Ryvkina 2001). Due to the factor of relations shadowization and their closeness a 
special world opposing the official institutional system is being created. As part of that special "closed world" of authoritative interaction a situation in which the shadowy forms of interaction stimulates officials and politicians to finally leave "the legal space and create centers of resources reallocation out of law control and shadow forms of state regulation» is formed (A.I. Solovyov, 2011).

As part of the functioning of the State machinery unspoken form a network of shadow interaction with a variety of hidden forms and rules appears. And «the "tacit life of this system is dynamic and diverse," bureaucratic moles "of many different breeds had dug lots of underground tunnels through which "the sector" intensively communicate, exchange classified information, personnel continuously flow from the ruling apparatus in the non-state bureaucracy and back ... Today these pretenders spread so widely that do not cause not only surprise, but even any significant public interest. Mediocrity of what is going on, obviously dulled the vigilance of society in respect of any bureaucracies of no legal state, but in fact constitute a single unit wit supporting public administration, constantly communicating with its staff, information, technology » (A.I. Solovyov, 2011).

This opposition to the official order of authoritative-law interaction in modern political systems is primarily not an open confrontation, but rather hidden, i.e. "invisible" (for official statistics) practices of the institutional and regulatory rules "bypass". As the famous French anthropologist N. Rouland pointed out today frank violation of the law is fraught with danger. In most cases one tries to avoid law (N. Rouland, 1988). According to it, the development and expansion of shadow relations undermine and eventually destroy the formal political and legal foundations of society, destabilize and randomize the order of authoritative interaction in all spheres of public life.

As a rule, shadow relationships arise where there are urgent social problem with no ordinary (official) forms and methods of solving, or where formal methods are in conflict with the established practice of interaction, shared by the majority of political subjects and there where the official ways establish a sufficiently complex or unknown (not approved by social interaction) procedures for the implementation of subjective and collective interests and needs.

In this situation, in respect to $\mathrm{V}$. Radaev, there starts the process of continuous deformalization of rules and regulations in which the formal rules and relationships are largely replaced by shadow and eventually incorporated into a stable system of informal relations. In this case, most of the political actors do not perform or perform occasional prescriptions of formal rules and procedures, but it does not lead to their total rejection, "rather, they are incorporated into a more complex system of restrictions, most of which is informal in nature"; and formal rules and relations act in this case as the method and language of public justification, camouflage of shadow relations (V. Radaev, 2001).

With regard to such concepts as "shadow law" and "non-legal practice", they are a kind of shadow relations in state-legal society activity. It is obvious that the political and legal functioning of society is a complex concept, reflecting the totality of forms and methods of political and legal life of the nation. At the same time the spheres of subjects functioning contain a complex of all political and legal phenomena, including both positive and negative components; it reflects not only ordered but also disordered (random, spontaneous and so on.) basis of the processes occurring in society.

- Illegal practices of authoritative interaction owe their origin to the existing diverse and multi-vector processes (socio-cultural, legal, political, economic, and so on.) in society, that develop in parallel, sometimes concur, in other cases are contrary to each other, forming an insurmountable conflict-between space in the context of which the subjects interact. For example, L. Friedman believes that the occurrence of illegal practices of private informal systems (shadow right) in the political life of society is associated with the formation of "voids" or manifestation of "weakness" in the official system of public-authoritative regulation / management of social processes.

In most cases private systems that conflict with the official system, occur because of authority vacuum, a lack of proper or adequate settlement of certain sectors of social interaction. For example, this "means that there were certain groups of people who believe that the official law is too weak or fall into the wrong hands" (L. Friedman, 1993).

In general, according to L. Friedman's oppinion, society, like nature, abhors a vacuum and violations of the agreement; the collapse of authority system creates a vacuum. In such circumstances there are two ethno-political process: positive - formation of a vacuum in the resolution of the conflict situation requires abandon informal norms and create a formal system able to cope with the situation; and negative - occurrence of a in the official system or its inadequacy in solving social and political problems, conflicts, contradictions forces the society to form a shadow structures and mechanisms to bypass the formal system.

In this regard the formation of informal practices and structures occurs to be a society answer to the problems in social interaction which does not obtain a suitable solving through the formal system. However, this process acquires negative characteristics when informal practice transform into illegal practices, i.e. opposed to the formal legal system. In these cases, the existing formal institutional system loses its justification and legitimacy, credibility and effectiveness, it is being replaced by natural processes of informal justice, informal procedures and tools for conflict resolution, etc. 
Pointing to this, L. Friedman notes that popular justice, which is out-of-control can take many forms, reaching blind, ruthless practice of lynchings, the French popular tribunals, etc. Formation and development of illegal practices, taken as a socio-cultural space, represents a shadow law. In other words, shadow practices as constituted, stable and reproducible system of shadow relations, form the shadow law. In its turn, the illegal space can be defined as a set of illegal practices and prevailing customs of cooperation, different ways of perceiving the world of law and politics, unrecorded in the objectified (positive) law and official political order of interaction or contradiction.

A characteristic feature of informal practices are short-term emerging of authoritative relationships. For example, pursuing a well-defined goal, official, citizen or entrepreneur can use illegal channel of authoritative communication to achieve a particular goal. At the same time, while systematic or long-term contacting between the participants of shadow relations sufficiently strong / stable relationship appear, taking the form of clannish union, almost independent of external political situation or personal preferences of members of shadow relations. However, such local interpersonal formations are capable of widening, self-organizing, hierarching and defence mechanisms forming.

Consideration of informal rules begins with recognition of the principle that the state does not have the exclusive monopoly on the right in a society that, in contrast to the official rules of subjects relationships, there is still quite a large array of rules and regulations governing social and political relations that solving social conflicts and contradictions. However, it is necessary to remember that the term "law" can be applied to various kinds of processes - even to sufficiently informal, very far from the formal legal system. Thus, for example, Friedman notes: "there are quite a number of different kinds of informal courts scattered throughout the country. Some of them are managed by the machinery of religious organizations. Orthodox Jews, for example, can bring the dispute to the court for the rabbinate to settle it down. The Catholic Church has a developed system of canon law. Ecclesiastical courts decide whether the marriage be annulled "( L. Friedman, 1993).

As V.M. Baranov marks out, "shadow law as a negative manifestation of juridical pluralism, a dangerous kind of negative informal rules, a set of anti-social rules has became widespread" (V.M. Baranov, 2002). Meanwhile, the existence of such a phenomenon as a shadow right indicates the process of institutionalization of the shadow authoritative relations, giving them clear contours of coherent anti-system of law and official state policy. At the same time it should be noted that shadow right as the right to the official, there is to streamline complex, but not legal, as the shadow of a hierarchical system that ensures public need for social control. At the same time it should be noted that shadow right as the official right occurs to streamline complex, not legal, but shadow hierarchical system that ensures public need for social control. However, unlike the official law the shadow law represents the interests of particular social groups, contrary to the public interest, creating gaps in the social space. Shadow norms, being hidden from the public, are not corrected in public, which allows the strong political and economic actors to formulate shadow criminal rules of social interaction, contrary to morality, social justice and the public interest.

Due to the nature of the legal system, while translating into the language of rights this or that authoritative relations, existing in society, they not only being corrected, generalized and narrowed, but in principle in such a short time cannot encode the general modality of political management and regulatory structuring of social processes in the rule of law. Therefore, the modern legal regulation is often divorced from the actual practice and by and large is only a guide, the desired outcome, rather than the actual mechanism. From the theoretical and methodological point of view selection and juxtaposition of these two political and legal spaces is associated usually with conflictness of existing formal institutionalauthoritative system, which asserts a certain order of relations and practice of subjects, implemented at the level of everyday practices.

\section{Concluding Remarks}

1. The functioning of state authority is implemented through the formal (public and legal) and extra-legal government activities. Extra-legal form of the functioning of authoritative institutions is an activity of public authority, not associated or mediated by right (although in some cases it may not be regulated by law, but at the same time does not contradict the current constitutional and legal system and the spirit of the institutional and political order), having both formal and public and informal character; it is of a broad (generic) concept with respect to such forms as "informal", "shadow", "non-legal" activities, and can have both negative and positive influence on the development of the political system of society. In Russian state-legal process extralegal forms are consistently reproduced as the immanent characteristics of the state ruling, caused by ideocratical (ideas, images, symbols, spiritual and moral dominants of political and legal consciousness) and practical (the practice of creating temporary, emergency and other public institutions of authorities to solve emerging issues, risks, threats, priority lines) elements of the national political culture. 
2. Reasons of informal practices occurrence are different. First, it is illegal (informal) relations arising due to the inability to regulate certain group of public relations by law. Second, informal practices may result from inadequate institutionalization of public forms of public administration, their discrepancy with established society types, models of public-authoritative interaction. Third, shadow practices may arise as society's response to the inefficiency of the legal public institutions of authority. Fourth, the development of the latter stimulates the weakness of formal institutions, the growing of costs of regulatory orientation for professional work of civil servants involved in the solution of complex problems. Furthermore, the processes of informal and shadow forms of power interaction is affected by the weakness of civil society institutions, which manifests itself as a low level of civic engagement, undeveloped forms of social control over the functioning of the state machinery, and the inability (because of legal and institutional - the objective reasons, or because of subjective one - the lack of proper skills, traditions, political participation, etc.) of public institutions and structures to participate in decision-making significant managerial, in strategic national programs and in projects in monitoring the implementation of the latter at various stages of their implementation.

\section{References}

Baranov, V.M., 2002. Shadow Right. Nizhny Novgorod.

Baranov, P.P., 2005 Problems of the Theory of Justice and Legal Education. Rostov-on-Don, Part II. V. 2.

Vitchenko, A.M., 1982. Theoretical Problems of the State Authority Studying. Saratov.

Homerov I.N., 2002. The State and Government: backgrounds, features, structure. M.

Ivannikov, I.A., 1995. In Search of the Ideal State System of Russia (in the history of Russian political and legal thought in the second half of the XIX century).

Lux, S. 2010. Power: a radical approach. M.

Lyubashits, V.Y., 2011. The Concept of State Authority, its features and varieties: problems of theory // North Caucasus Law Gazette. 2001. № 1.

Malyi, A.F., 2001. The State Authority as a Legal Category // The State and law. № 3.

Pivovarov, Y.S., 2006. Russian Political Tradition and Modernity. M.

Radaev, V., 2001. Deformalization of Rules and Tax Evasion in Russia Economic Activity // Problems of Economics. № 6.

Ryvkina, R.V., 2001. Russian Society as a Shadow Socio-Economic System // World Economy and International Relations. № 4.

Solovyov A. I., 2011. Latent Structure of Government, or the Game of Shadows on the Face of the Authorities // Political Studies. № 5.

Friedman, L., 1993. Introduction to American Law. M.

Schmitt, C., 2000. Political Theology. M.

Barker, R., 2003. Legitimating Identities. The Self-Presentations of Rulers and Subjects. Cambridge: Cambridge Univ. Press.

Kononova, O. and Yakimova, Z. 2013. Competence as an Object for Assessmen and Measuremen in Training Quality Control System//World Applied Sciences journal. T.27. pp. 536-540.

Kirsanova, L. and Korotina O., 2014. On the Contents of the Protest Conscience in Russia. World.

Lipset, S.M., 1994. The Social Requisites for Democracy: Economic Development Revisited: 1993 presidential address // American sociological review. Vol. 59. № 1.

Ostrom, E.A., 2010. A Long Polycentric Journey // Annual review of political science. Vol. 13. № 1.

Rouland, N., 1988. Anthropologie Juridigue. Paris: Presses universitaires de France.

Weatherford, M.S., 1992. Measuring Political Legitimacy // American political science review. Vol. 86. №1. 